ORIGINAL ARTICLES

\title{
Chronic illness and hospital readmission rate by adult age groups
}

\author{
Jayasree Basu* \\ Center for Evidence and Practice Improvement, Agency for Health Care Research and Quality, Rockville, Maryland, USA
}

Received: February 19, 2019

DOI: $10.5430 /$ ijh.v5n2p12
Accepted: April 24, 2019

URL: https://doi.org/10.5430/ijh.v5n2p12

Online Published: May 19, 2019

\begin{abstract}
Objective: The study provides a comprehensive assessment of readmission risks of patients by nonelderly adult and elderly age groups admitted with different chronic condition types and multiple chronic condition (MCC) burdens.

Methods: The study examines the all-cause readmission risks of hospitalized adult patients in 18-64 and 65 and above age groups admitted for any cause having three mutually exclusive chronic condition types: Ambulatory Care Sensitive Condition (ACSC); non-ACSC, and non-chronic. Using 2009 hospital discharge data from HCUP-SID of AHRQ, linked to the contextual and provider data from HRSA, a multilevel logistic regression model is applied on data pooled over 5 states adjusting for patient, hospital, and community characteristics.

Results: The hospitalized elderly with chronic ACSC has higher risks of readmissions than those without, or relative to the nonelderly with chronic ACSC. However, nonelderly adults faced steeper increases in risks of readmissions than the elderly in response to increased MCC burden, irrespective of types of chronic conditions.

Conclusions: A lower number of ACSCs is associated with higher reduction in the risks of readmission in the elderly than in the nonelderly adults. Management of chronic conditions in general is associated with reduced readmission risks across all age groups, more so for nonelderly adults.
\end{abstract}

Key Words: Hospital readmissions, Multiple chronic conditions, Ambulatory Care Sensitive Conditions, Population subgroups, Administrative data

\section{INTRODUCTION}

A readmission is considered to be clinically related to a prior admission and potentially preventable if there was a reasonable expectation that it could have been prevented by one or more of the following: (1) the provision of quality care in the initial hospitalization, (2) adequate discharge planning, (3) adequate post discharge follow-up, or (4) improved coordination between inpatient and outpatient health care teams.

Chronic conditions include both physical and behavioral health conditions that last a year or more. Chronic conditions require ongoing medical care and/or limit physical activities. Patients with multiple chronic conditions (MCC) have two or more chronic illnesses at the same time. Using both patient and area level data, ${ }^{[1,2]}$ past studies had found MCC to be a major driver of readmissions. Past studies also found readmission risks to be higher among elderly than nonelderly adults because of poorer health status and increased number of comorbidities. ${ }^{[2]}$

In this study, we particularly focus on a group of chronic con-

\footnotetext{
*Correspondence: Jayasree Basu, Ph.D.; Email: Jayasree.Basu@ahrq.hhs.gov; Address: Center for Evidence and Practice Improvement, Agency for Health Care Research and Quality, 5600 Fishers Lane, Rockville, Maryland 20857, USA. 
ditions identified as subgroups of Ambulatory Care Sensitive Conditions (ACSCs), a well-used proxy measure for potentially preventable admissions that has been used in research, policy development and program design. These conditions are those that could exacerbate and lead to hospitalization if not prevented through better management in an ambulatory care setting. Thus appropriate ambulatory care intervention could prevent or reduce the need for hospital admission (or inpatient care) for these health conditions (such as diabetes or chronic obstructive pulmonary disease). The concept was first introduced in New York in the early 1990s as an indicator of population level access to outpatient care, even though these indicators are based on hospital inpatient data. ${ }^{[3]}$

\subsection{New contribution}

This is the first study to provide a comprehensive assessment of the risks of readmissions of patients by age groups as they were initially admitted to the hospital with chronic ACSC versus other or no chronic conditions, and with different levels of chronic condition burden. To our knowledge, no study had yet examined differences in readmission risk of patients hospitalized with different types of chronic conditions, within and across population subgroups. From a policy perspective, it is important to identify and target those patients more vulnerable to risks of readmissions across population subgroups with specific chronic condition type and/or burden. Of particular policy interest are the chronic conditions that are amenable to better care management, improved delivery and access to care, so that such interventions could potentially reduce the readmission rates. The research and policy questions of interest will be to examine whether and to what extent readmission risks could be smaller if patients are admitted with fewer chronic ACSCs (presumably through better access to primary care), and whether patients in different age groups and with different MCC burdens should be targeted differently.

\subsection{Objectives and hypotheses}

The purpose of this study is to assess the risks of readmissions associated with chronic condition type and MCC burden by adult age groups. We particularly focus on two broad adult age groups: non-elderly adults (18-64) and elderly (65+), since literature suggests a significant disparity in ACSC hospitalization rates between the two groups, with elderly hospitalized at a higher rate than the nonelderly. ${ }^{[4]}$ Previous literature provide evidence that, across age groups, readmission risk is higher for patients with chronic condition than those without. ${ }^{[1]}$ Also, because elderly have more chronic conditions, they have higher readmission risks than nonelderly adults. ${ }^{[2,5]}$

Not much is known whether or how chronic conditions bur-

Published by Sciedu Press den by types of chronic conditions are associated with readmission risks across age groups. It is not known, for example, whether 1) the hospitalized elderly with chronic ACSC will have higher risks of readmissions than those without, or relative to the nonelderly with chronic ACSC, or whether 2) readmission risks will increase uniformly across elderly and nonelderly in response to accumulation of chronic conditions (MCC), specifically within and across chronic condition categories (ACSCs and non-ACSCs).

We expect readmission risks to show different patterns across chronic condition type and age groups, particularly across ACSCs and non-ACSCs because of differences in prevalence and the intensity of these conditions across age groups. This is demonstrated in Table 1 (to be described later), showing elderly more prone to be admitted with ACSC than nonelderly. However, as Table 1 shows, elderly in general has greater number of chronic conditions at initial hospitalization, and as a result, elderly are also more prone to be admitted with non-ACSCs than nonelderly. Thus it is not clear how readmission risks by chronic type should vary within each age group or across age groups. One, however, could expect that, elderly may have some chronic illnesses that are at more advanced stages and thus could flare up more frequently than those of nonelderly adults, causing a higher likelihood of readmissions.

The next question to examine is whether increasing MCC burden plays different roles across chronic type and age groups. Several observations here may lead to a hypothesis here. First, 1) the nonelderly with chronic conditions could have worse socioeconomic and health status than the elderly on initial admission. A previous study has found lower readmission rates in areas with higher concentration of 65-74 than 18-34 adults. ${ }^{[2]}$ Studies also found the association between socio-economic status and mortality stronger among nonelderly than elderly; ${ }^{[6]} 2$ ) since multimorbidities among the elderly also include functional impairment, disability, and other geriatric syndromes, ${ }^{[7]}$ chronic conditions alone do not adequately predict the readmission risks in the elderly. Thus, it is likely that nonelderly adults could experience higher increases in risks of readmission than the corresponding elderly, as the number of chronic conditions increased. It is not known, however, whether the same pattern should follow across ACSCs versus non-ACSCs, which is a subject of interest to examine.

In this study, we test these hypotheses using multivariate models, controlling for patient, hospital, and area characteristics. We particularly control for case mix of the patient on the index admission in order to identify the independent association between chronic conditions and readmission risks. 
Table 1. Admissions by chronic condition categories and age: Summary statistics, 2009: 5-state total

\begin{tabular}{|c|c|c|c|c|c|c|c|c|c|}
\hline \multirow{2}{*}{$\begin{array}{l}\text { Age } \\
\text { Chronic } \\
\text { Condition } \\
\text { categories }\end{array}$} & \multicolumn{3}{|c|}{18 and above } & \multicolumn{3}{|c|}{$18-64$} & \multicolumn{3}{|c|}{65 and above } \\
\hline & $\mathbf{N}$ & $\begin{array}{l}\text { Mean \# of } \\
\text { Chronic } \\
\text { conditions }\end{array}$ & $\begin{array}{l}\text { Readmissi } \\
\text { on rates }\end{array}$ & $\mathbf{N}$ & $\begin{array}{l}\text { Mean \# of } \\
\text { Chronic } \\
\text { conditions }\end{array}$ & $\begin{array}{l}\text { Readmissi } \\
\text { on rates }\end{array}$ & $\mathbf{N}$ & $\begin{array}{l}\text { Mean \# of } \\
\text { Chronic } \\
\text { conditions }\end{array}$ & $\begin{array}{l}\text { Readmissi } \\
\text { on rates }\end{array}$ \\
\hline $\begin{array}{l}\text { At least one } \\
\text { chronic } \\
\text { ACSC }\end{array}$ & $\begin{array}{l}594,134 \\
(7.39 \%)\end{array}$ & 6.413 & $8.8 \%$ & $\begin{array}{l}262,226 \\
(5.6 \%)\end{array}$ & 5.496 & $6.99 \%$ & $\begin{array}{l}331,908 \\
(10.14 \%)\end{array}$ & 7.129 & $10.21 \%$ \\
\hline $\begin{array}{l}\text { At least one } \\
\text { any other } \\
\text { chronic } \\
\text { condition }\end{array}$ & $\begin{array}{l}6,267,851 \\
(78.0 \%)\end{array}$ & 4.878 & $7.01 \%$ & $\begin{array}{l}3,355,826 \\
(70.45 \%)\end{array}$ & 3.947 & $5.93 \%$ & $\begin{array}{l}2,912,025 \\
(89.0 \%)\end{array}$ & 5.943 & $8.26 \%$ \\
\hline $\begin{array}{l}\text { No chronic } \\
\text { condition }\end{array}$ & $\begin{array}{l}1,173,505 \\
(14.6 \%)\end{array}$ & 0.00 & $2.13 \%$ & $\begin{array}{l}1,145,433 \\
(24.05 \%)\end{array}$ & 0.00 & $2.07 \%$ & $\begin{array}{l}28,067 \\
(0.86 \%)\end{array}$ & 0.00 & $4.92 \%$ \\
\hline Total & $8,035,490$ & 4.298 & $6.43 \%$ & $4,763,490$ & 3.105 & $5.06 \%$ & $3,272,000$ & 6.011 & $8.42 \%$ \\
\hline
\end{tabular}

Note. Rounding errors are present. In this table, we exclude missing age or gender but retain cases with a missing DRG, missing diagnosis or missing payer. Discharges for patients who died at an initial stay or whose initial stay occurred in December of 2009 were also disqualified because they could not be followed for 30 days. We drop cases for persons living out-of-state and drop the cases with missing zip codes, and/or with missing person ID.

\section{DATA AND METHODS}

The study uses hospital discharge data of patients in five US states: California (CA), Florida (FL), Missouri (MO), New York (NY), and Tennessee (TN), for 2009, a year immediately preceding the ACA, in the adult age group (18 and above). The data are obtained from the Healthcare Cost and Utilization Project (HCUP) State Inpatient Databases (SID) of the Agency for Healthcare Research and Quality, ${ }^{[8]}$ linked to the contextual and provider data from Health Resources and Services Administration (HRSA) by the primary care service areas (PCSAs) (described below). The year 2009 represents the latest year prior to the start of Centers of Medicare \& Medicaid Services' Hospital Compare program of public reporting of hospital performance on 30-day readmissions. ${ }^{[9]}$ The states were selected based on the availability of 2009 HCUP-SID data to calculate readmission.

We focus on all-cause hospital readmission within 30 days of a discharge from an index hospital admission of any type. Approaches defining readmissions often use broad definitions, such as the one used by $3 \mathrm{M}^{[10]}$ in defining potentially preventable readmissions (clinically related to a prior admission), or the one CMS is using for specific admission types (using all-cause readmissions). There is a literature comparing readmission approaches, comparing all-cause readmissions to potentially preventable readmissions. ${ }^{[1-14]}$ Readmission among adults could occur due to many different conditions as reported in recent literature. ${ }^{[15]}$ Some more current studies have therefore focused on readmission after all-cause admissions. ${ }^{[16,17]}$

There are a total of up to 23 chronic conditions, including both physical and behavioral health conditions, which are captured in the discharge record of patients in the HCUP data. These conditions are identified by a Chronic Condition Indicator which categorizes all ICD-9-CM diagnoses codes as chronic or not chronic. Of these, chronic ACSCs are defined by AHRQ's prevention quality indicators (PQI), originally defined by ICD-9 codes by Billings et al. ${ }^{[3]}$ and later validated by AHRQ. ${ }^{[18]}$ The ACSCs (alternatively called $P Q I s)$ can include both acute and chronic conditions. The HCUP data designate the following 9 conditions as chronic PQI: PQI \#01 Diabetes Short Term Complications; PQI \#03 Diabetes Long Term Complications; PQI \#05 Chronic Obstructive Pulmonary Disease (COPD) or Asthma in Older Adults; PQI \#07 Hypertension; PQI \#13 Angina without Procedure; PQI \#08 Congestive Heart Failure (CHF); PQI \#14 Uncontrolled Diabetes; PQI \#15 Asthma in Younger Adults; PQI \#16 Lower Extremity Amputation Among Patients With Diabetes. The rest of the chronic conditions not included in the PQI list are lumped together as non-PQI chronic conditions (or non-ACSC). Some of the chronic nonACSCs include chronic kidney disease, cancer, depression, and dementia.

\subsection{Study design}

Following a conceptual model developed in earlier research, ${ }^{[2]}$ a multivariate analysis was conducted combining characteristics of patients, their providers, and the areas where patients reside at the index admission. Patient characteristics are represented by need (health status and disease severity), predisposing (age, sex, race/ethnicity) and enabling factors (insurance status and median household income of the patient's ZIP Code), while three variables represent environmental characteristics of the PCSA: primary care provider (PCP) density, population density and urban/rural residence status. Two hospital-attributes: bed size, and teaching status, 
constitute provider factors. These variables are described in detail below.

A multilevel logistic regression model is applied on data pooled over 5 states and two age groups, adjusting for patient, hospital, and community characteristics. We used a unique geographic unit of patients' residence, PCSA, to obtain the contextual and provider data of patients that can be linked to data on patient characteristics. PCSA is defined as a contiguous area, usually consisting of multiple zip codes, such that a majority of the primary care of the residents is received within the area. ${ }^{[19]}$

\subsubsection{Outcome variable}

The outcome of interest for this study is the patient's risk of 30-day hospital readmission, defined as the probability of a hospital readmission from any cause within 30 days of discharge from an index hospital admission from any cause. A patent can be counted multiple times within the January to November observation period, ${ }^{[20]}$ however, only one readmission is counted within the 30-day period of each admission. In addition, a hospital stay may be a readmission for a prior stay and the index admission for a subsequent readmission. Certain categories of admissions/readmissions are excluded from our study sample, e.g., pregnancy related readmissions, trauma-related readmissions, ${ }^{[21]}$ and elective readmissions. These exclusions are necessary to focus only on unplanned and potentially avoidable readmissions in this study.

\subsection{Independent variables}

The independent variables of interest are 3 types of chronic condition characteristics of the patient at the index admission: ACSC Chronic, non-ACSC Chronic, and non-chronic. We stratify all hospitalized patients admitted for any cause by three mutually exclusive and exhaustive types of chronic conditions they had at initial admissions: 1) at least one chronic ACSC; 2) no ACSC but at least one chronic non-ACSC; 3) no chronic conditions.

We use a flag in the analytical file if a patient has an ACSC (PQI) chronic condition. The assignment of non-ACSC chronic conditions is made through a process of eliminating those with an ACSC (PQI) flag, which could have led to some biases and misalignment, as well as grouping of nonACSCs that are not clinically meaningful. In addition, some of these non-ACSC chronic conditions are also amenable to better management through primary care - thus PQI indicators are not comprehensive. On the other hand, some of these PQI conditions (e.g., Angina without procedures) are not necessarily a preventable condition in the elderly.

We also create a dichotomous variable indicating nonelderly or elderly age group to gauge the difference between the two age groups. Additionally, we create an ordinal variable showing number of chronic conditions on admission. This variable, denoted as MCC is defined following previous work ${ }^{[22]}$ in which chronic conditions on each discharge record were counted and grouped into 3 categories (0-1, 23,4 and above). In order to be consistent with rest of the analysis, we split MCC in 4 groups: 0, 1, 2-3, 4 and above.

\subsubsection{Covariates}

Several patient characteristics are used as covariates in the models including race, sex, insurance status, and income. Race is grouped into four categories: non-Hispanic white (reference), non-Hispanic black or African American, Hispanics, and other races (includes Asian or Pacific Islander, Native Americans and others). We exclude patients with missing race (about 1.19\%). Insurance status is grouped into five categories: private or commercial insurance (reference), Medicare, Medicaid, uninsured, and other payers consisting of charities and small public programs. Household income is another socio-economic characteristic of the patient which, in the absence of the individual level data, is measured at the zip code quartile levels of patient's resident area.

We also control for multiple factors representing patient's health status and disease severity: patient severity score as indicated by APR-DRGs severity index in the HCUP data base and reported in 4 categories: minor, moderate, major, extreme; patient's APR-DRG risks of mortality, also reported as minor (= reference), moderate, major, and extreme. In order to account for variations in severity and risks of mortality across base APR-DRGs, we added APR-DRG weights in the model, computed as aggregate average length of stay (to approximate case mix intensity) by APR-DRGs in five states. We use a variable on admission type where urgent and emergency admissions indicates higher severity. We simulate our results dropping some of the aforementioned health status variables.

To indicate contextual factors of a patient, we include several variables that reflected characteristics of the community (PCSA) patients are coming from. The major ones considered were whether patients came from a rural or an urban area, and area's primary care provide density and population density. Urban-rural status of the PCSA was indicated by a variable called urban-rural commuting area (RUCA), available from HRSA data and grouped into four categories ranging from urban to isolated rural areas. Primary care provider density was measured as the number of clinically active primary care physicians per 100,000 population, while population density was measured as thousands of total population per square mile land area. In addition to community characteristics, we also include hospital characteristics 
such as hospital bed-size, mortality rate, and teaching status. Hospital's bed-size is measured in three categories: small (reference), medium, and large, and teaching status is reported in three categories: rural, urban non-teaching, and urban-teaching, the first two combined as the non-teaching (reference) group.

\subsection{Study sample}

Table 1 shows the distribution of the overall study sample by chronic condition categories and age groups. To provide a general picture, only the exclusions footnoted in the table are applied in computing the entries. The table also shows the number of chronic conditions by these subgroups. Characteristics of the sample can be summarized as follows: 1) Elderly are more frequently admitted with chronic conditions than nonelderly adults; 2) A higher percentage of admission in the elderly than nonelderly are with at least one ACSC chronic condition (10.1\% vs. 5.6\%). Likewise, a higher percentage of admission in elderly than nonelderly are with at least one non-ACSC chronic condition (89\% vs. $70 \%)$; 3) On the other hand, a much lower percentage of admission in elderly $(0.86 \%)$ than nonelderly adults $(24 \%)$ are without a chronic condition; 4) More than $50 \%$ of elderly admissions were with 6 and more chronic conditions while nearly $30 \%$ of nonelderly admission were with 0 or 1 chronic condition; 5) Readmissions rate for patients with a chronic condition is higher than the corresponding rate for patients having no chronic conditions at the index admission; 6) Readmission rate overall is higher in the elderly than in nonelderly; 7) Despite a higher percentage of admissions for nonelderly adults than elderly are with no chronic condition, readmissions rates are higher for the elderly than the nonelderly.

\section{Results}

\subsection{Findings from the multivariate analysis}

We conduct two sets of analyses - Analysis I incorporates interaction terms with chronic condition categories and age group to assess the readmission risks associated with specific types of chronic condition and age group. Analysis II uses interactions between age groups, chronic condition type, and chronic condition burden (MCC) to assess the readmission risks associated with specific levels of MCC by types of chronic conditions and age group.

\subsubsection{Analysis I}

Table 2 and Figure 1 present findings from a multivariate analysis where we fitted a logistic regression model to estimate the risks of readmissions, incorporating interaction of chronic condition categories and age group, along with other confounding variables. The interaction terms in Table
2 show that compared to the elderly with no chronic conditions, the nonelderly with chronic conditions (both types) were significantly more likely to have readmissions.

Table 2. Logistic regression model results for 5 states: Odds ratios of all-cause 30-day readmission (vs. no readmission), 2009

\begin{tabular}{|c|c|}
\hline Items & $\begin{array}{l}\text { All adults }(18+) \\
\mathrm{N}=6,569,924^{\#}\end{array}$ \\
\hline \multicolumn{2}{|l|}{ PATIENT CHARACTERISTICS } \\
\hline Female & $0.94(0.91,0.93)^{*}$ \\
\hline Age & $1.003(1.0003,1.004)^{*}$ \\
\hline \multicolumn{2}{|l|}{ Race (Ref: white) } \\
\hline African American (AA) & $1.01(0.99,1.03)$ \\
\hline Hispanic & $0.93(0.91,0.95)^{*}$ \\
\hline Other race & $0.93(0.92,0.95)^{*}$ \\
\hline ACSC-Chrn & $1.32(1.23,1.40)^{*}$ \\
\hline Non_ACSC-chron & $1.13(1.06,1.20)^{*}$ \\
\hline \multicolumn{2}{|l|}{ Age_category (Ref: 65+) } \\
\hline Adult (18-64) & $0.82(0.76,0.87)^{*}$ \\
\hline ACSC_chron x Adult (18-64) & $1.16(1.08,1.24)^{*}$ \\
\hline Non_ACSC_chron x Adult (18-64) & $1.38(1.29,1.47)^{*}$ \\
\hline \multicolumn{2}{|l|}{ Insurance (Ref: private pay) } \\
\hline Medicare & $1.29(1.27,1.31)^{*}$ \\
\hline Medicaid & $1.32(1.29,1.34)^{*}$ \\
\hline Uninsured & $0.91(0.88,0.93)^{*}$ \\
\hline Other pay & $0.97(0.94,1.00)$ \\
\hline APRDRG_weight & $1.01(1.01,1.02)^{*}$ \\
\hline \multicolumn{2}{|l|}{ APRDRG Risk of Mortality (Ref: minor) } \\
\hline Moderate & $1.34(1.32,1.35)^{*}$ \\
\hline Major & $1.55(1.53,1.57)^{*}$ \\
\hline Extreme & $1.19(1.16,1.21)^{*}$ \\
\hline \multicolumn{2}{|l|}{ APRDRG severity (Ref: minor) } \\
\hline Moderate & $1.27(1.25,1.28)^{*}$ \\
\hline Major & $1.52(1.50,1.54)^{*}$ \\
\hline Extreme & $1.55(1.52,1.58)^{*}$ \\
\hline \multicolumn{2}{|l|}{ Admission type (Ref: Elective) } \\
\hline Emergency & $1.36(1.34,1.38)^{*}$ \\
\hline Urgent & $1.34(1.31,1.36)^{*}$ \\
\hline Other & $0.78(0.69,0.88)^{*}$ \\
\hline \multicolumn{2}{|l|}{ HOSPITAL CHARACTERISTICS } \\
\hline Teaching & $1.05(1.03,1.06)^{*}$ \\
\hline \multicolumn{2}{|l|}{ Bed size (Ref: small) } \\
\hline Medium & $1.02(0.99,1.04)$ \\
\hline Large & $1.04(1.02,1.06)^{*}$ \\
\hline \multicolumn{2}{|l|}{ COMMUNITY CHARACTERISTICS } \\
\hline \multicolumn{2}{|l|}{ Rural/Urban PCSA (Ref: urban) } \\
\hline Suburban & $0.97(0.94,1.003)$ \\
\hline Large city & $0.94(0.92,0.97)^{*}$ \\
\hline Small city & $0.87(0.85,0.92)^{*}$ \\
\hline Rural/isolated & $0.91(0.88,0.95)^{*}$ \\
\hline \multicolumn{2}{|c|}{$\begin{array}{l}\text { Median Household Income national quartile } \\
\text { for Patient Zip code (ref: } \$ 0-39,999 \text { ) }\end{array}$} \\
\hline$\$ 40,000-49,999$ & $1.00(0.98,1.01)$ \\
\hline$\$ 50,000-65,999$ & $0.99(0.98,1.02)$ \\
\hline$\$ 66,000+$ & $0.98(0.96,1.00)$ \\
\hline Population density & $1.00(1,1.00)^{*}$ \\
\hline PCP density & $1.00(0.99,1.00)$ \\
\hline
\end{tabular}




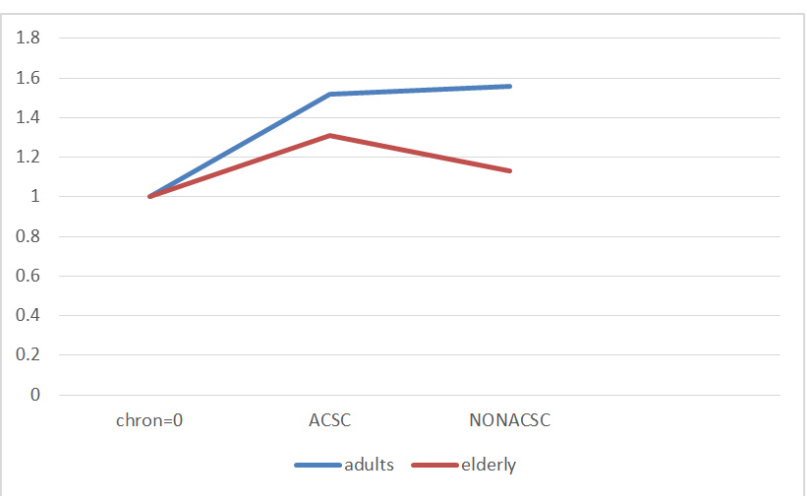

Figure 1. Odds ratios of readmissions by chronic condition type and Age group, 2009

Derived from regression results reported in Table 2, using post estimation "lincom" command in STATA. All entries are statistically significant at $p<.01$.

As an extension of Table 2, we compute an alternative representation of the odds ratios from the same regression model based on combining the interaction with separate covariate estimates - suitable for making cross-age-group and crosschronic-type comparisons of readmission rates. The adjusted odds ratios by each age group and chronic condition category, derived from this analysis, are reported in Figure 1, showing a cross-age group comparison by chronic condition type, standardized to a baseline level of no chronic condition. Figure 1 shows the odds ratios of readmission of elderly with at least one chronic ACSC was $31 \%(\mathrm{OR}=1.31, p<.01)$ higher than the elderly with no chronic conditions, while the corresponding odds ratio for nonelderly was $52 \%$ higher (OR $=1.52, p<.01$ ) than nonelderly with no chronic conditions. The same pattern followed with patients with at least one non-ACSC where the corresponding risks of readmissions for elderly and nonelderly were respectively $13 \%$ and $56 \%$ ( $p<.01$ for both) higher than the corresponding groups with no chronic conditions. Thus, we find that, relative to having no chronic conditions, nonelderly with at least one chronic condition (ACSC or non-ACSC) experience a higher odds ratios of readmissions than the corresponding elderly. Of note is the finding that while risks of readmissions do not vary much across types of chronic conditions for the nonelderly $(\mathrm{OR}=1.52,1.56)$, elderly with a non-ACSC experience a lower risk $(\mathrm{OR}=1.13, p<.01)$ than those with an ACSC $(\mathrm{OR}=1.32, p<.01)$.

\subsubsection{Analysis II}

Tables 3 and 4 as well as Figure 2 present findings from a logistic regression model where readmission risks were assessed by performing three-way interactions between age groups, chronic condition type, and MCC levels. Table 3 shows selected findings from this analysis, which are further

Published by Sciedu Press summarized into Table 4 and Figure 2. Table 4 and Figure 2 respectively report adjusted odds ratios of readmissions and marginal probabilities (or predicted rates) of readmissions derived from this model for each age group by chronic condition category and MCC level.

Table 3. Selected logistic regression model results for 5 states: Odds ratios of all-cause 30-day readmission (versus no readmission), 2009

\begin{tabular}{|c|c|}
\hline Items & $\begin{array}{l}\text { All adults }(18+) \\
\mathrm{N}=6,569,924^{\#}\end{array}$ \\
\hline \multicolumn{2}{|l|}{ Age-category (Ref: elderly (65+)) } \\
\hline Nonelderly Adult (18-64) & $0.78(0.73,0.83)^{*}$ \\
\hline \multicolumn{2}{|l|}{ Chronic categories (Ref $=0$ chronic) } \\
\hline ACSC-Chronic_1 & $1.24(1.04,1.47)^{* *}$ \\
\hline ACSC-Chronic_2-3 & $1.23(1.15,1.33)^{*}$ \\
\hline ACSC-Chronic_4+ & $1.37(1.29,1.46)^{*}$ \\
\hline NONACSC-Chronic_1 & $1.02(0.96,1.09)$ \\
\hline NONACSC-Chronic_2-3 & $1.05(0.98,1.12)$ \\
\hline NONACSC-Chronic_4+ & $1.19(1.12,1.27)^{*}$ \\
\hline \multicolumn{2}{|c|}{$\begin{array}{l}\text { INTERACTIONS (Age Category X chronic category; Ref: elderly } \\
\text { with no chronic conditions) }\end{array}$} \\
\hline Nonelderly X ACSC-Chronic_1 & $0.94(0.78,1.14)$ \\
\hline Nonelderly X ACSC-Chronic_2-3 & $1.17(1.08,1.28)^{*}$ \\
\hline Nonelderly X ACSC-Chronic_4+ & $1.21(1.13,1.29)^{*}$ \\
\hline Nonelderly X NONACSC-Chronic_1 & $1.30(1.22,1.39)^{*}$ \\
\hline Nonelderly X NONACSC-Chronic_2-3 & $1.50(1.40,1.60)^{*}$ \\
\hline Nonelderly X NONACSC-Chronic_4+ & $1.42(1.33,1.52)^{*}$ \\
\hline
\end{tabular}

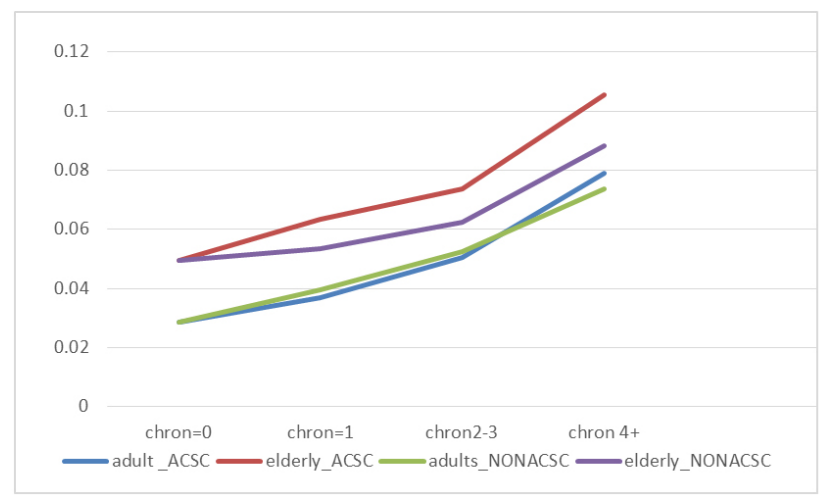

Figure 2. Marginal probabilities of readmissions (or adjusted readmission rates) by age group, chronic type, and MCC, 2009

The data in this chart are derived from Table 3 using "margins" options in STATA. All entries are statistically significant at $p<.01$.

Table 4 demonstrates that odds ratios for readmission increased for both nonelderly and elderly as MCC accumulated from none to a level of 4 and above. However, the increase was sharper for nonelderly than elderly, irrespective of the type of chronic condition (66\% vs. $37 \%$ for ACSC; $70 \%$ 
vs. $19 \%$ for non-ACSC). In addition, among the nonelderly, odds ratio of readmission increased more sharply when they were admitted with at least one non-ACSC than with at least one ACSC, while the corresponding increase was higher for elderly with an ACSC than a non-ACSC.

Figure 2 demonstrates the same pattern by showing that, despite predicted marginal probability of readmission (or adjusted readmission rates) being higher among elderly than nonelderly at all levels of MCC, the nonelderly experienced a much steeper increase in the marginal probability (with respect to MCC) than elderly. In addition, at all levels of MCC, elderly with at least one ACSC had higher adjusted rates of readmission than elderly with at least one non-ACSC. Further tests also reveal that the difference is risks of readmissions for elderly between MCC levels 2-3 vs. 1 are not statistically significant $(p>.05)$ for either ACSC or non-ACSCs.

\subsection{Other findings}

Patient characteristics, such as age, severity of illness, were uniformly related to higher readmissions across age groups. The associations of race and insurance types with readmissions varied across age groups. While Medicare patients had higher odds of readmissions than privately insured among the elderly, Hispanics had lower odds than whites. Uninsured had lower odds of readmissions across age groups than the privately uninsured. Higher income was marginally associated with lower readmissions among the elderly, while rural patients were less likely to be readmitted than patients in urban areas.

Table 4. Odds ratios of readmissions by chronic condition type, burden, and age group

\begin{tabular}{llllll}
\hline Age group & Chronic condition type & MCC = 0 & MCC = 1 & MCC = 2-3 & MCC = 4+ \\
\hline Nonelderly & ACSC & 1 & $1.17^{*}(1.07,1.27)$ & $1.45^{*}(1.38,1.52)$ & $1.66^{*}(1.61,1.72)$ \\
Nonelderly & Non-ACSC & 1 & $1.33^{*}(1.29,1.38)$ & $1.57^{*}(1.53,1.62)$ & $1.70^{*}(1.65,1.75)$ \\
Elderly & ACSC & 1 & $1.24^{* *}(1.04,1.47)$ & $1.23^{*}(1.15,1.32)$ & $1.37^{*}(1.29,1.46)$ \\
Elderly & Non-ACSC & 1 & $1.02(0.96,1.09)$ & $1.05(0.98,1.12)$ & $1.19^{*}(1.12,1.28)$ \\
\hline
\end{tabular}

Note. Derived from regression results reported in Table 3, using post estimation "lincom" command in stata-14. ${ }^{*} p<.01,{ }^{* *} p<.05$

\section{Discussion}

The study generates several interesting findings, some of which are supported by hypotheses previously made. As expected, the adjusted readmission rates were found to be higher for elderly than nonelderly, and higher for elderly with chronic ACSC than elderly with non-ACSC. The finding could attest to the supposition that the elderly might be having more frequent episodes of advanced chronic illnesses in the ACSC category than in the non-ACSC category or with respect to nonelderly adults. Studies had found that certain ACSC conditions such as diabetes or cardiovascular diseases could lead to mortality, decline in functional status, and increased risks of institutionalization among the elderly. ${ }^{[23,24]}$

Interestingly, although a higher proportion of elderly than nonelderly are admitted with a chronic condition, and despite the elderly generally having higher readmission risks, nonelderly faces a steeper increase in readmission risks than elderly, when compared with corresponding groups without any chronic conditions. Apparently counterintuitive, this finding is reflective of the fact that nonelderly had a much lower readmission risk than elderly at the baseline (when MCC $=0$ ), as illustrated in Table 1 . Thus, adding chronic condition will increase the readmission risks of nonelderly more than the elderly. The findings hold irrespective of the type of chronic conditions (ACSC or non-ACSC).

This finding holds throughout different MCC levels as well. As hypothesized, in addition to having a lower baseline risk of readmissions, nonelderly adults in younger age groups could face a greater proportionate increase in risk of readmissions with respect to MCC because of a combination of factors including a lower socioeconomic status, lack of insurance, and lifestyle. Although we controlled for insurance status, younger adults may have more access barriers determined by social factors and unmeasured confounding than are captured by uninsured status in our model. A test run shows this indeed to be true as readmission risks are higher for 18-34 and 35-44 age groups having 2 or more MCC (relative to those with 0-1 MCC level), as compared with any other age groups (see Figure 3). Moreover, because elderly could have worse functional status than nonelderly, MCC alone may not increase the readmission risks as fast among elderly as in nonelderly. Thus, it is possible that a higher proportion of nonelderly will be readmitted only when they have a higher MCC burden.

The study has several limitations including the heterogeneity bias in assigning non-ACSC categories discussed earlier. In addition, the post-discharge care coordination and transitional care could not be directly measured. Although we included a PCP density variable for the area, the role of 
primary care clinicians and care teams following patient discharge needs to be better addressed including the role of non-physician clinicians. Our findings related to primary care is important in this study to the extent we show that elderly with fewer ACSCs at the index admission will likely have lower readmission risks (and so better primary care access would be valuable) than those with non-ACSC chronic conditions. Among socio demographic factors, education or literacy levels were not included to avoid collinearity with median income. Median income, measured at the zip code level, could have potentially failed to capture the variations in socioeconomic status explained better by individual income. The study also could not identify Medicaid patients who were previously uninsured and moved into Medicaid at hospitalization. Future studies should examine whether these patterns changed after hospital readmission rate reduction program was implemented. Although there is no apparent reason to expect a change, increased insurance coverage with Affordable Care Act and stricter control on hospital readmission rates could potentially influence readmission patterns by population subgroups.

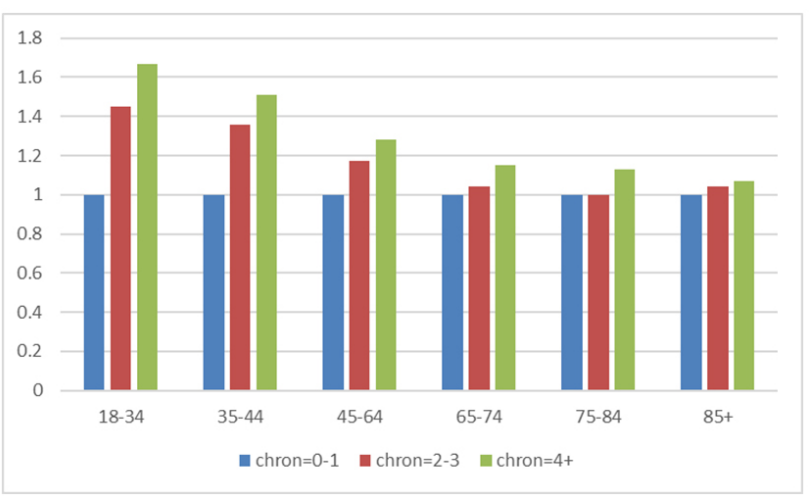

Figure 3. Odds ratios of readmissions by age groups and MCC, 2009

\section{Conclusion}

The study shows that the readmissions risk for patients with a chronic condition is higher than the corresponding risk for patients having no chronic conditions at the index admission. Management of the number of chronic conditions that could be prevented through ambulatory care will be of more benefit among the elderly than for nonelderly adults to control the risk of 30-day readmissions. Management of the number of chronic conditions in general will be beneficial across all age groups, more so for nonelderly adults. Future study should build on these results to determine whether changes implemented after 2009 made a difference in this pattern.

\section{ACKNOWLEDGEMENTS}

This research is funded by the author's employer, the Agency for Healthcare Research and Quality (AHRQ). The views expressed in this paper are those of the author. No official endorsement by any agency of the federal government is intended or should be inferred. The author acknowledges the state data organizations that participate in the HCUP State Inpatient Databases: California Office of Statewide Health Planning and Development, Florida Agency for Health Care Administration, New York State Department of Health, Tennessee Hospital Association, and Missouri Hospital Industry Data Institute. The author also acknowledges the data and programming support provided by Social and Scientific Systems, Inc. in Maryland. The author also thanks the AHRQ peer reviewers, Drs. Theodore Ganiats, Arlene Bierman, and Anne Elixhauser for their very helpful comments.

\section{Disclosure STATEMENT}

The article or parts of it has not been published elsewhere but was presented at the IHEA world congress in Boston, 2017.

\section{CONFlicts of InTERest Disclosure}

The author declares no conflicts of interest.

\section{REFERENCES}

[1] Friedman B, Jiang HJ, Elixhauser A. Costly Hospital Readmissions and Complex Chronic conditions. Inquiry. 2008; 45(4): 408-421. PMid:19209836. https://doi.org/10.5034/inquiryjrnl_45 .04 .408

[2] Basu J, Avila RM, Ricciardi R. Hospital Readmission rates in US states: Are Readmissions Higher where more Patients with Multiple Chronic Conditions Cluster? Health Services Research. 2016; 51(3): 1135-51. PMid:26481190. https://doi .org/10.1111/1475-6 773.12401

[3] Billings J, Zeitel L, Lukomnik J, et al. Impact of Socioeconomic Status on Hospital Use in New York City. Health Affairs. 1993; 12(1): 162-73. PMid:8509018. https://doi.org/10.1377/hl

Published by Sciedu Press thaff.12.1.162

[4] Basu J. Has Access to Care Changed in Minority Communities? A study of Preventable Hospitalizations over time in Selected States. Journal of Ambulatory Care Management. 2014; 37(4): 314-330. PMid:25180647. https://doi.org/10.1097/JAC. 0000000000 000024

[5] Basu J, Hanchate A, Bierman A. Racial/Ethnic Disparities in Readmissions in US Hospitals: The Role of Insurance Coverage. Inquiry 2018; 55: 1-12. PMid:29730971. https://doi .org/10.1177/00 46958018774180

[6] Duncan GJ, Daly MC, McDonough P, et al. Optimal Indicators of Socioeconomic Status for Health Research. American Journal of Public Health. 2002; 92(7): 1151-1157. PMid:12084700. https: 
//doi.org/10.2105/AJPH.92.7.1151

[7] Koroukian SM, Warner DF, Owusu C, et al. Multimorbidity redefined: prospective health outcomes and the cumulative effect of co-occurring conditions. Prev Chronic Dis. 2015; 12: E55. PMid:25906436. https://doi.org/10.5888/pcd12.140478

[8] Agency for Healthcare Research and Quality (AHRQ). Agency for Healthcare Research and Quality: Healthcare Cost and Utilization Project (HCUP). 2004, Rockville, MD. Available from: http://www.hcup-us.ahrq.gov/db/state/siddbdoc umentation.jsp, Accessed March 2015.

[9] DeVore AD, et al. Has Public Reporting of Hospital Readmission Rates Affected Patient Outcomes? Analysis of Medicare Claims Data. Journal of the American College of Cardiology. 2016; 67(8): 963-972. PMid:26916487. https://doi.org/10.1016/j.jacc .2015 .12 .037

[10] Goldfield NI, McCullough EC, Hughes JS, et al. Identifying potentially preventable readmissions. Health Care Financing Rev. 2008 Fall; 30(1): 75-91.

[11] Mull HJ, Chen Q, O’Brien WJ, et al. Comparing Two Methods of Assessing 30-Day Readmissions: What is the Impact on Hospital Profiling in the Veterans Health Administration? Medical Care. 2013; 51(7): 589. PMid:23604016. https://doi.org/10.1097/ MLR.0b013e31829019a4

[12] Chen Q, Mull HJ, Rosen AK, et al. Measuring readmissions after surgery: do different methods tell the same story? The American Journal of Surgery. 2016; 212(1): 24-33. PMid:26506557. https://doi.org/10.1016/j.amjsurg.2015.08.020

[13] Davies S, Saynina O, Schultz E, et al. Implications of metric choice for common applications of readmission metrics. Health Services Research. 2013; 48(6pt1): 1978-1995. PMid:23742056. https ://doi.org/10.1111/1475-6773.12075

[14] Rosen AK, Chen Q, Shwartz M, et al. Does Use of a Hospitalwide Readmission Measure Versus Condition-specific Readmission Measures Make a Difference for Hospital Profiling and Payment Penalties? Medical Care. 2016; 54(2): 155-161. PMid:26595224. https://doi.org/10.1097/MLR.0000000000000455
[15] Hines AL, Barrett ML, Jiang HJ, et al. Conditions With the Largest Number of Adult Hospital Readmissions by Payer, 2011 Statistical Brief, \#172, AHRQ. Available from: http://www.ncbi.nlm.nih .gov/books/NBK206781/2009

[16] Jencks SF, Williams MV, Coleman EA. Rehospitalizations among patients in the Medicare fee-for-service program. N Engl J Med. 2009; 60: 1418-28.

[17] Lasser KE, Hanchate AD, McCormick D, et al. The effect of Massachusetts health reform on 30 day hospital readmissions: retrospective analysis of hospital episode statistics. BMJ. 2015; 350. PMid:24687184. https : //doi .org/10.1136/bmj .g2329

[18] Agency for Healthcare Research and Quality, AHRQ Quality Indicators: Guide to Prevention Quality Indicators: Hospital Admission for Ambulatory Care Sensitive Conditions, October 2001, AHRQ Pub No. 02-R0203, Revision April 17, 2002.

[19] Goodman DC, Mick SS, Bott D, et al. Primary Care Service Areas: A New Tool for the Evaluation of Primary Care Services. Health Services Research. 2003; 38(1): 287-310. PMid: 12650392. https://doi .org/10.1111/1475-6773.00116

[20] Elixhauser A, Steiner C. Readmission to U.S. Hospitals by Diagnosis, Healthcare Cost and Utilization Project Statistical Brief \# 153, 2013, AHRQ.

[21] Friedman B, Jiang HJ, Steiner CA, et al. Likelihood of Readmission after First Discharge: Medicare Advantage vs. fee-forservice patients. Inquiry. 2012; 49(3): 202-13. PMid:23230702. https ://doi.org/10.5034/inquiryjrnl_49.03.01

[22] Steiner CA, Friedman B. Hospital Utilization, Costs, and Mortality for Adults With Multiple Chronic Conditions, Nationwide Inpatient Sample, 2009. Prev Chronic Dis. 2013; 10: 120292. PMid:23618542. https://doi.org/10.5888/pcd10.120292

[23] Kirkman MS, Briscoe VJ, Clark N, et al. Diabetes in Older Adults. Diabetes Care. 2012; 35(12): 2650-2664. PMid:23100048. https: //doi.org/10.2337/dc12-1801

[24] Boult C, Kane RL, Louis TA, et al. Chronic Conditions that Lead to Functional Limitation in the Elderly. Journal of Gerentology. 1994; 4(1): M28-M36. https ://doi.org/10.1093/geronj/49.1.M2 8 